\title{
MEASURING LANDCOVER INDICIES OF ADAMAWA STATE USING REMOTE SENSING AND GEOGRAPHIC INFORMATION SYSTEM (GIS) TECHNIQUES
}

\author{
A. A. Musa ${ }^{1}$ and A. L. Tukur ${ }^{2}$ \\ ${ }^{1}$ Department of Surveying and Geoinformatics, Federal University of Technology, Yola \\ ${ }^{2}$ Department of Geography, Federal University of Technology, Yola
}

\begin{abstract}
Areas covered by marshlands, highlands and plains were needed in each local government area (LGA) as the bases for allocating funds to the LGAs. In recognition of the fact that ground survey techniques are very labor intensive, consumes a lot of time and generally inconveniencing, a GIS technique was adopted. Satellite images of the state were sub divided along the LGA boundaries. Highlands were located visually and digitized into vector polygons, and then by using the polygon tool of the GIS, areas covered by the polygons were determined. The image classification routine was used to isolate marshlands. By going to the 'Raster Tools...' menu and specifying the Display/Edit Raster Attributes' tool, the areas covered by the marshlands were also determined. Areas covered by plains on the other hand were determined indirectly. The area covered by highlands (already computed) was subtracted from the total area of the LGA by using manual qualitative deduction. Since highlands and plains are mutually exclusive, the result of the subtraction is the area covered by plains. It was observed that LGAs with the highest percentage of marshlands are those which R.Benue pass through. It was also observed that marshlands were more plentiful on plains than on the highlands.
\end{abstract}

\section{INTRODUCTION}

In Nigeria there are three tiers of administrative units (i.e. governments) - the Federal, State and Local governments. The local governments are the lowest arm of the three tiers. The Revenue Mobilization and Fiscal Commission (RMAFC) uses three land cover classes as part of the indices for allocating revenue to states and local governments. The land cover classes include highlands, marshlands and plains. The bases for this choice of classes are not far fetched. Highlands (excluding plateaus) are the usual habitats of wild animals. Likewise because of the difficult terrain such areas have hitherto been largely untouched by man. The increasing trend of environmental degradation nationwide has made preservation of part of our environment an attractive policy. Development in such areas will therefore be very challenging. Marshlands on the other hand are good for agriculture because of the presence of water. For an effective and efficient policy on agriculture, the size and location of marshlands is imperative. Lastly, the plains are the traditionally preferred dwelling places of man. Most of the cities of Nigeria are found on plains. Planning for the expansion of an existing city, town or even village, or establishing a completely new settlement must put into consideration the size and location of existing plains.

In a bid to ensure that revenue dispensed to it is based on the correct measurements of these indices, the Adamawa state government decided to generate the indices using the most accurate and fastest method possible. Measuring areas covered by highlands, marshlands and plains directly by ground survey methods is not only tedious but error prone. While on the ground, it is difficult to determine, talk less of 
calculating, areas covered by marshlands covering an expanse of land as extensive as Adamawa State. Measuring the perimeter of the highlands, on the other hand will take several months with numerous field men. Ever conscious of the implication of working with wrongly measured indices, and faced with limited time within which to submit the required indices to the appropriate government agency the Adamawa State government decided to use a remote sensing and GIS approach. This paper therefore attempts to derive the required indices using a remote sensing and GIS approach and discusses the implication of the results.

The use of the GIS in making measurements on spatial data so as to derive needed indices is well documented in various literatures. By analyzing the SPOT XS image of Abuja using the IDRISI GIS package, Adewuyi (2004) was not only able to measure the lengths of the various categories of roads, but also counted the number of road junctions in the area. The data was used for designing a logistic plan for internal security. Likewise, in an attempt to monitor the gradual build-up of urban sprawl along the Delimi river, in J os, J eb(2004) successfully used the GIS to measure areas covered by urban build-up areas on three selected years (i.e. 1961, 1965 and 1991). Based on the indices derived, he concluded that urban sprawl had increased by 47.04\% between 1961 and 1991. With the aim of planning towards improving the living standards of urban slum dwellers, Ujjwal et al (2004) attempted to identify the urban slums in Dehradum - India. By combining visual interpretation techniques alongside the GIS and IKONOS satellite images, they were not only able to count the number of slums; but were also able to measure the size of each of the slums. Worried by the rate of depletion of mangrove forests and fuelled by the desire to conserve mangrove areas for agricultural activities and aquaculture, Vadtapudi (2003) attempted to extract indices regarding areas of change between the years 1995 and 2002. By using the Indian remote sensing (IRS) satellite images together with ERDAS Imagine GIS package, to conduct change detection analysis, he successfully extracted change statistics of various landuse/landcover classes that exist in the study area. Other studies where spatial information were successfully quantified include Rajiv and Deelesh (2003) who were able to identify and quantify accident black spots and Narayanam et al (2003) who used the GIS to quantify traffic congestion.

Studies in which manual techniques were used to classify Adamawa State into its different landforms are very few. One of such studies is the one by Tukur (1999). Using mainly topographic sheets covering the state, he employed analogue cartographic means to classify the state into hills, uplands and plains. A map of Adamawa State classified into its various landforms was thus created. The middle part of the state where the R. Benue passes constitute the plains of the state, while towards the north and south of the R. Benue are uplands. The eastern border of the state reside the mountain ranges.

\section{Study Area}

For the purpose of administrative convenience, Nigeria was divided into 36 states. One of such states is Adamawa state. Located in the north eastern part of Nigeria, Adamawa state lies between $7^{\circ}$ and $11^{\mathrm{o}} \mathrm{N}$ and between $11^{\circ}$ and $14^{\mathrm{o}} \mathrm{E}$. The eastern border of the state also doubles as an international boundary between Nigeria and Cameroun. At the northern part of the state is Borno state; at the west is Gombe 
state, while at the south and south west is Taraba state. Most of the highlands in the state are located along the eastern border, while the lowlands fall within the central part of the state where the valley of river Benue is located.

\section{METHODOLOGY MATERIALS}

The materials used were LANDSAT ETM+ satellite image taken in November/ December 2004. The images were acquired from the National Centre for Remote Sensing (NCRS) J os and they were in ERDAS format at the time of acquisition. Apart from the images, two GIS software packages (i.e. ERDAS IMAGINE 8.6 \&ARCVIEW 3.2a) and a HP laptop computer were also used.

\section{CREATING THE AREA OF INTEREST (AOI):}

Since the project area is Adamawa state, there is the need to isolate areas covered by the state from other areas outside the state. This will form the area of interest upon which further geospatial analysis will be carried out. Using the ERDAS software, seven scenes of LANDSAT ETM+ images were mosaicked to form a single seamless whole named Adamawa.img. This was achieved through the 'Data Prep/Mosaic Images' module. The image file Adamawa.img not only covered the state but also covered a reasonable proportion of the neighboring states. The first task therefore was the removal of images covering neighboring states from the main image Adamawa.img

A scanned political map of Adamawa State (produced by the Adamawa State Ministry of Lands \& Survey) was geo-referenced. Using the geo-referenced map as background, the boundaries of the state and local government areas (LGAs) were digitized onto a plain vector file named Adamawa.vec. Adamawa.vec was digitally overlaid on Adamawa.img. This allowed the analyst see the image of the land mass of Adamawa State by virtue of the background satellite image and at the same time see the boundaries of the state and its LGAs using the vector file at the foreground.

While still keeping the viewer containing Adamawa.img and Adamawa.vec open, a new 'AOI' file was opened in edit mode and overlaid on the viewer. An AOI file is a unique feature of ERDAS. Basically, it allows an analyst define his area of interest accurately. This AOI file can then be used later in various analyses. Using the appropriate tools the boundaries of the state were traced as carefully as possible onto the AOI file. The same was done to the boundaries of each of the LGAs. The AOI for the state was named Adamawa.aoi and the AOI file of each of the LGA were named after the LGA. The 'Data Prep/Subset Image' module was finally activated and by specifying Adamawa.img as the image to subset and Adamawa.aoi as the area of interest required, a satellite image of the state was created (See Fig 1). This newly created image was named Adamawa state.img. This became the main data from where the required indices were measured.

\section{IDENTIFYING REQUIRED LANDCOVER CLASSES Marshlands}

The image file Adamawa_State.img was subjected to an unsupervised image classification routine. Unsupervised image classification is the technique of allowing the computer to classify an image on its own into various spectral signature groups. Fifteen clusters were generated from the classification. Each of the clusters (class) were then inspected one after the other using the flicker tool. Among the 15 clusters 
inspected only cluster 7 depicted known areas of marshland. Cluster 7 was therefore isolated for more vigorous verification. This verification was in the form of physically visiting some of the marshland sites and crosschecking their image position if it corresponds to marshland areas. Three areas of known marshlands were visited and UTM coordinates taken using the GPS. The areas include the surroundings of Lake Gerio, the confluence between River Belwa and River Benue, and lastly the marshy plains of Numan. The GPS coordinates were used to locate these areas on the classified image. All the areas mentioned were clearly depicted by cluster 7. Cluster 7 was therefore taken as the cluster which depicts the spectral response pattern for marshlands. Pixel values of the other clusters were thus reclassed to zero, making them invisible. (See Fig 2)

\section{Highlands:}

Visual interpretation technique was used for identifying highlands. Due to the position of the sun in the sky, the sun's radiation hits the topography at an angle. This creates shadows (hill shading effect) thereby making it possible to visually see areas covered by highlands (Fig $1 \&$ Fig 3). The boundary of the highlands is however not as well defined as that of the state or LGA boundaries. It is left to the discretion of the analyst to determine where to begin carving out the highlands. This is one of the fundamental problems in converting field based (raster) data to discrete based (vector) data.

\section{Plains}

Plains and highlands are mutually exclusive. Thus all areas that are not grouped as highlands were first isolated. The areas that do not fall within the marshlands were then taken as plains.

\section{MEASURING THE REQUIRED INDICES}

While a vector-GIS approach was applied to the measurement of the areas covered by highlands and plains; a raster-GIS approach was considered more appropriate for measuring areas covered by marshland. The average heights of the highlands were extracted from topographic maps.

\section{Area Covered By Marshlands:}

Using the AOI file for each LGA, on the classified map for marshlands (Fig 2), the area covered by marshlands for each LGA were extracted. For the twenty one local government areas that form Adamawa State twenty one raster files were thus created for marshlands. While each of the files was displayed in the viewer, the "Raster/ Tools.. / Display/ Edit Raster Attributes" module was activated to display the computed coverage of the marshland in each LGA.

\section{Area Covered By Highlands \& Plains:}

Using the AOI file for each LGA, on the main satellite image (Fig 1), the satellite image of a required LGA was extracted (Fig 3) from the main image. Two blank vector files (one for measuring highlands and the other for measuring total area covered by the LGA) were overlaid on the image. Once a vector file is overlaid on a geo-referenced raster file, it automatically inherits the reference coordinates of the raster file. On the first vector file, the boundaries of the LGA were digitized as vector polygons. Similarly in the second vector file, all the highlands in the LGA were 
digitized as vector polygons. While the vector files were still displayed in the viewer, the "Vector/Tools.. / Show Vector attributes" module was activated to display the area coverage required.

\section{RESULTS \& DISCUSSION:}

Generally, marshlands are concentrated mostly within the middle section of the state, where the two major rivers (i.e. R. Benue and R. Gongola) are located. The River Benue passes through about seven LGAs, i.e. Fufore, Yola north, Yola-south, Girei, Demsa, Numan and Lamurde. While R. Gongola passes through Shelleng, Guyuk and Numan LGAs. A look at Table 1, reveals that indeed these are the LGAs with the highest land mass covered with marshland. Tributaries from these rivers are most often responsible for the marshlands in other parts of the state. While the LGA with the largest marshland coverage is Lamurde with about $246 \mathrm{sq} \mathrm{km}$ followed by Demsa with $235.31 \mathrm{sq} \mathrm{km}$ of marshland; areas like Mubi-South and Maiha either have no marshland at all or have marshlands that are so insignificant that the satellite image could not depict it.

Toungo LGA which is the largest LGA in the state with area coverage of 5665.37sq $\mathrm{km}$, has only $1022.37 \mathrm{sqkm}$ of plains, out of which $30.07 \mathrm{sqkm}$ are marshlands. The bulk of Toungo is rugged highlands. This is a sharp contrast to Fufore - the second largest LGA in the state- with 4656.21 sqkm of plains. Generally the highlands are concentrated along the eastern border of the state forming a natural boundary between Cameroun and Nigeria. As anticipated, marshlands were not pronounce in highlands.

\section{CONCLUSIONS AND RECOMMENDATIONS}

The time it will take a typical cartographer to reduce the topographic sheets to an appropriate scale before merging them together to produce a single map of Adamawa State is more than enough for a GIS analyst to produce all the required indices. In terms of speed, the GIS technique is faster because of its ability to automate certain aspects of the cartographic process. The reliability of the data derived however depends on the reliability of other ancilliary data used. For instance, it is from the LGA boundary map of the state that areas of interest (AOI) of each LGA were derived. The technique used in getting these boundary maps relies on boundary descriptions by natural features, rather than precise coordinates. Also proliferation of boundary disputes between LGAs attest to the fact that whatever boundary maps being used is still not acceptable. These limitations are indirectly transferred into the GIS process of measuring the indices. However, considering the use to which the indices will be put (i.e. for computing revenue), errors of few acres will not result in any substantial loss or gain in revenue.

It must be stressed that the lack of a reliable and well maintained geographic database to fall back on is the main challenge facing the adoption of GIS techniques in the state. The present practice is to derive fresh data each time a GIS analysis requires such data. In most cases the data will be generated by those who have no proper knowledge of the kind of data they are generating, neither do they have the kind of equipment that will allow them generate it to the required accuracy. Unfortunately the GIS can only be as good as the data that it is fed with. It is for this reason that this paper recommends the establishment of a geographical database 
unit of the government. The unit will have linkages with relevant ministries with the sole aim of having access to their pool of experts and equipment, all with the primary objective of creating and maintaining a robust database for the government.

\section{REFERENCES}

Adewuyi, T. O. (2004): Capability of Remote Sensing Data for Logistic Planning in An Internal Security Operation pp341. In Olubiodun Ayeni, Peter Nwilo, Ademola Omojola \& James Olaleye (Edit); Geoinformation for Sustainable Development in Africa. African Association of Remote Sensing of the Environment.

Jeb. D. N. (2004): The Assessment of Urban Encroachment on the Delimi River, J os, Plateau State. Nigeria Using Geographic Information System. Pp523 In Olubiodun Ayeni, Peter Nwilo, Ademola Omojola \& James Olaleye (Edit); Geoinformation for Sustainable Development in Africa. African Association of Remote Sensing of the Environment.

Narayanam. R; Udayakumar. R; Kumar. K and Subbaraj. L (2003); Quantification of Congestion Using Fuzzy Logic and Network Analysis Using GIS.

http:// www.gisdevelopment.net/ application/ utility/ transport/mi03130.htm

Paul, L., Micheal, G., David, M. and David, R. (2002): The Geographic Information System and Science. J ohn Wiley \& Sons.

Tukur. A. L. (1999): in Adebayo \& Tukur (Edit) Adamawa State in Maps Chapter 4: Landforms

Rajiv, G. and Deelesh, M. (2003): Evaluation of Accident Black Spots on Roads Using Geographic Information Systems (GIS). http:// www.gisdevelopment.net/application/ utility/transport/mi03038.htm

Ujjwal, S., Sadhana, J . and Sokhi, B. S. (2004): Identification/ Mapping of Slum Environment Using IKONOS satellite Data: A Case of Dehradun, India. http:// www.gisdevelopment.net/application/ environment/pp/m:04011pf.ht $\underline{\mathrm{m}}$.

Vadlapudi, S. (2003): Identification and Quantification of Changes in Mangrove Forest Using Remote Sensing - A case study near Kakinada Bay, Andhra Pradesh, India. http:// www.gisdevelopment.net/application/ environment/ wetland/mi03075 pf.htm 


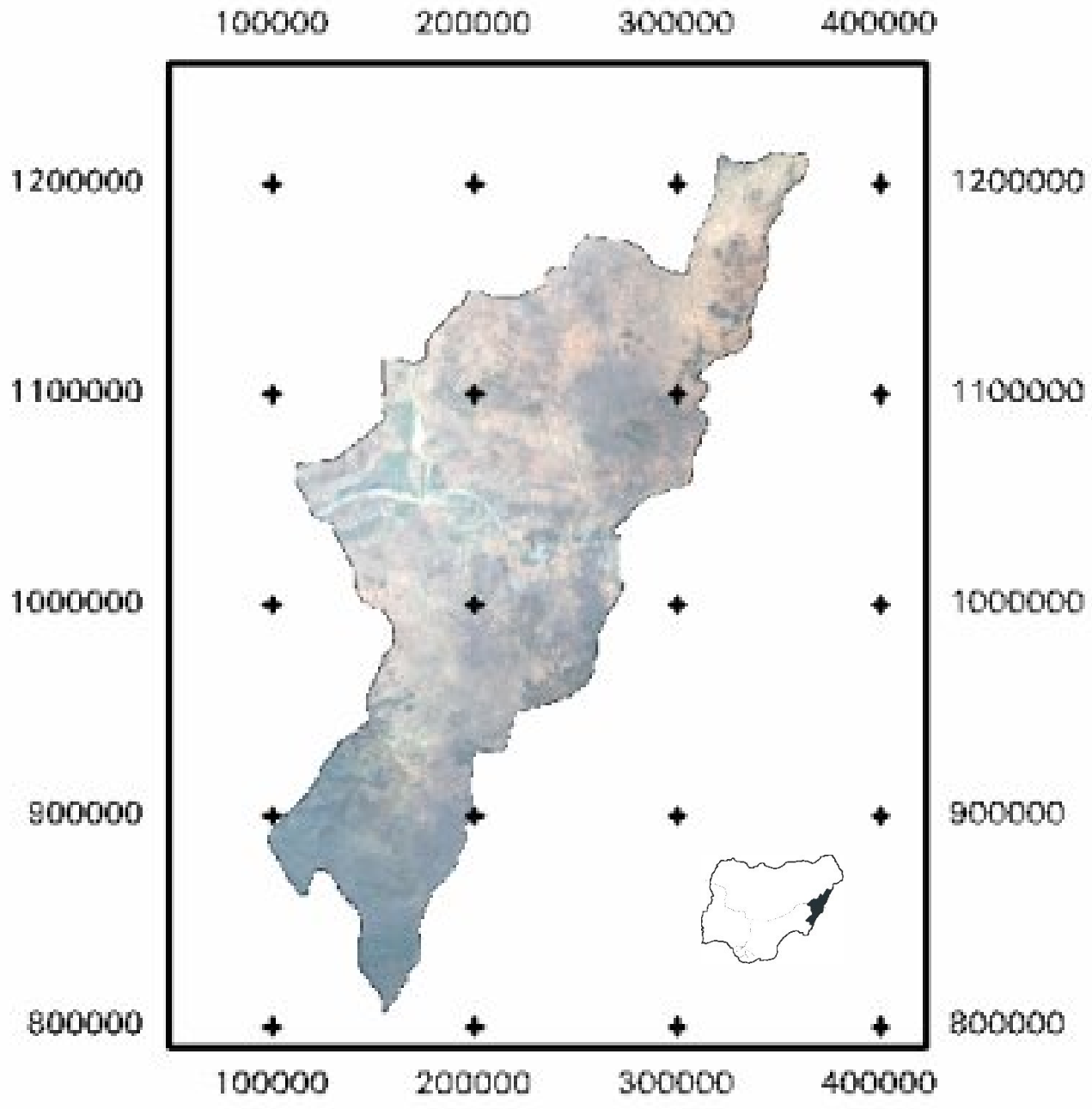

Fig1: Satellite image of Adamawa State of Nigeria 


\section{$100000 \quad 200000 \quad 300000$}

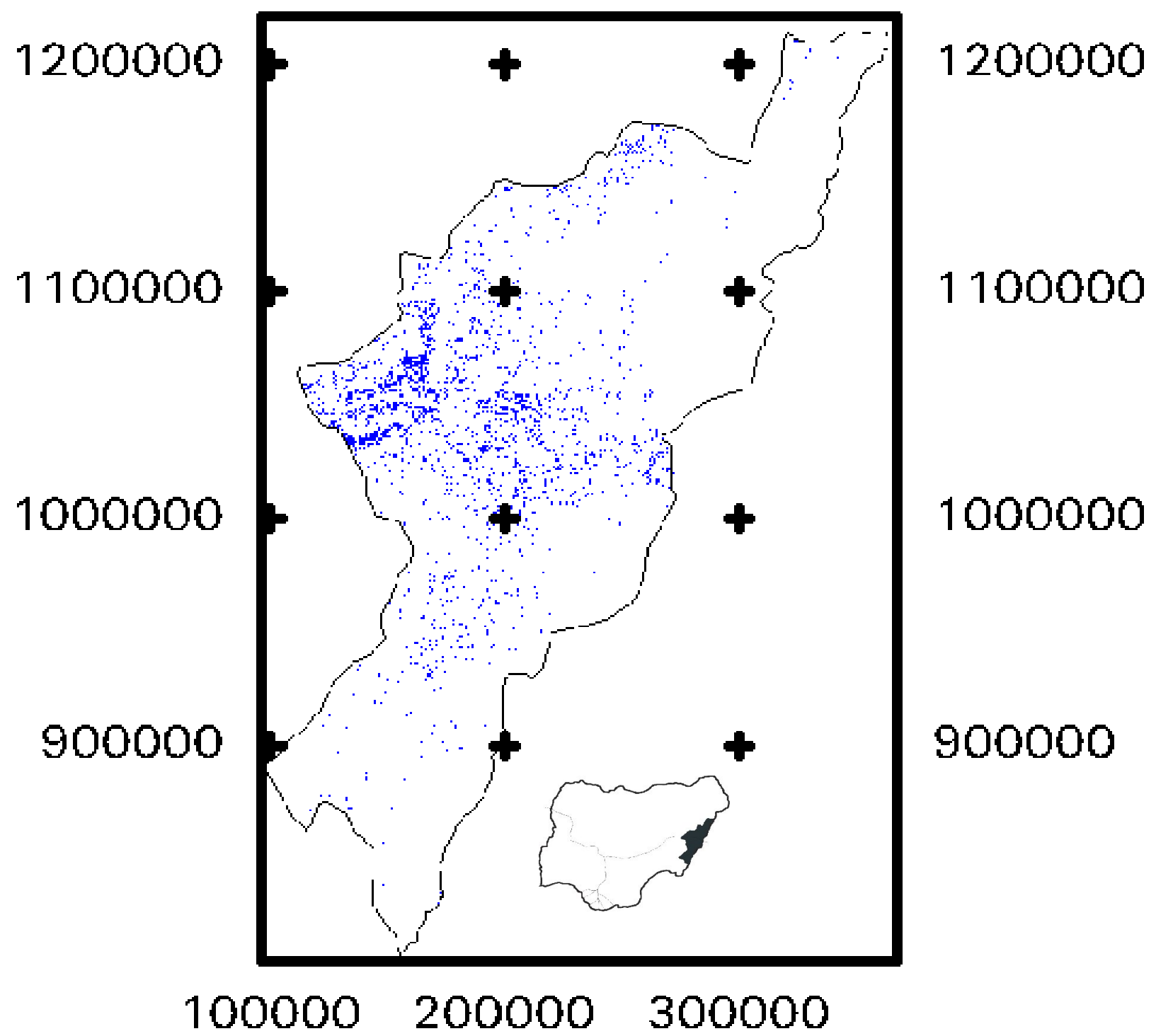

Fig 2: Map of Adamawa State showing areas with marshlands 


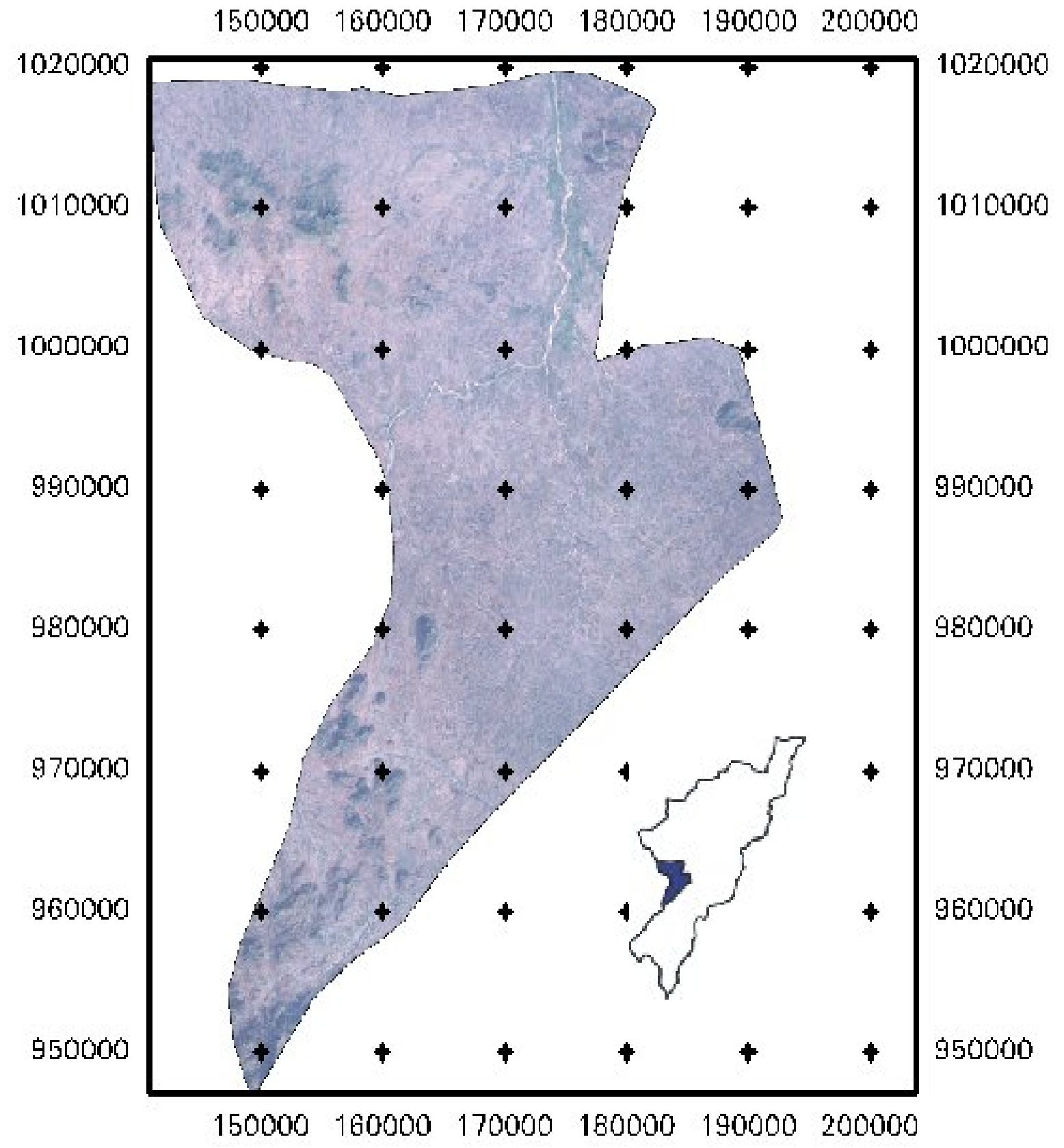

Fig 3: Satellite image of Mayo-Belwa LGA. A typical LGA extracted from the image of Adamawa State using the AOI file.

Table 1: BASIC STATISTICAL DATA ON ADAMAWA STATE 
FUTY J ournal of the Environment, Vol. 4, No. 1, 2009

(c) School of Environmental Sciences, Federal University of Technology, Yola-Nigeria. ISSN 1597-8826

\begin{tabular}{|l|l|l|l|l|l|l|l|l|l|}
\hline LGA & $\begin{array}{l}\text { Plain } \\
\mathbf{( s q} \\
\mathbf{k m})\end{array}$ & \%Plain & $\begin{array}{l}\text { Highland(sq } \\
\mathbf{k m})\end{array}$ & \%Highland & $\begin{array}{l}\text { Marshland } \\
\text { (sq km) }\end{array}$ & $\begin{array}{l}\text { \% } \\
\text { Marshland }\end{array}$ & $\begin{array}{l}\text { Area } \\
\text { (sq } \\
\text { km) }\end{array}$ & $\begin{array}{l}\text { \% } \\
\text { Total }\end{array}$ & $\begin{array}{l}\text { Mean } \\
\text { Ht }\end{array}$ \\
\hline Demsa & 1665 & 87.6 & 0 & 0 & 235.31 & 12.38 & 1900.31 & 100 & 250 \\
\hline Fufore & 4437.41 & 90 & 513.11 & 9.92 & 218.8 & 4.23 & 5169.32 & 100 & \\
\hline Ganye & 1043.44 & 51.8 & 922.8 & 45.87 & 45.23 & 2.25 & 2011.47 & 100 & 1036 \\
\hline Gerei & 920.73 & 79.9 & 123.83 & 10.7 & 107.08 & 9.29 & 1151.64 & 100 & 520 \\
\hline Gombi & 1816.5 & 92.9 & 90.50 & 4.6 & 46.5 & 2.4 & 1953.5 & 100 & \\
\hline Guyuk & 602.5 & 76.11 & 90.91 & 11.5 & 98.13 & 12.4 & 791.54 & 100 & \\
\hline Hong & 2581.58 & 93.76 & 114.5 & 4.1 & 57.12 & 2.0 & 2753.2 & 100 & \\
\hline Jada & 2089.18 & 71.4 & 759.81 & 26 & 77.12 & 2.6 & 2926.11 & 100 & 990.5 \\
\hline Lamurde & 344.42 & 29.32 & 584.27 & 49.7 & 246 & 20.9 & 1174.69 & 100 & 488 \\
\hline Madagali & 578.29 & 59.24 & 393.15 & 40.27 & 4.66 & 0.47 & 976.10 & 100 & 876.5 \\
\hline Maiha & 567.53 & 40.97 & 817.47 & 59 & 0.0 & 0.0 & 1385 & 100 & \\
\hline $\begin{array}{l}\text { Mayo- } \\
\text { Belwa }\end{array}$ & 1186.51 & 69.69 & 447.41 & 26.28 & 68.53 & 04.02 & 1702.45 & 100 & 983 \\
\hline Michika & 572.46 & 52.9 & 506.67 & 46.82 & 2.92 & 0.2 & 1082.05 & 100 & \\
\hline $\begin{array}{l}\text { Mubi- } \\
\text { North }\end{array}$ & 602.19 & 65.14 & 321.46 & 34.78 & 0.67 & 0.07 & 924.32 & 100 & 867 \\
\hline $\begin{array}{l}\text { Mubi- } \\
\text { South }\end{array}$ & 320.9 & 61.95 & 197.09 & 38.05 & 0.0 & 0.0 & 517.99 & 100 & 899.5 \\
\hline Numan & 741.68 & 78.9 & 4.08 & 0.43 & 194.24 & 20.6 & 940 & 100 & \\
\hline Shelleng & 759.79 & 48.31 & 719 & 45.7 & 93.69 & 5.9 & 1572.48 & 100 & 548.5 \\
\hline Song & 1529.44 & 35.36 & 2716.92 & 62.8 & 78.64 & 1.8 & 4325 & 100 & 716.5 \\
\hline Toungo & 992.3 & 17.51 & 4643 & 81.95 & 30.07 & 0.53 & 5665.37 & 100 & 960 \\
\hline $\begin{array}{l}\text { Yola- } \\
\text { North }\end{array}$ & 104.77 & 93.67 & 0.0 & 0.0 & 7.08 & 6.3 & 111.85 & 100 & 200 \\
\hline $\begin{array}{l}\text { Yola- } \\
\text { South }\end{array}$ & 645.94 & 89.83 & 0.0 & 0.0 & 73.06 & 10.16 & 719 & 100 & 200 \\
\hline Total & 24347.1 & & 13965.98 & & 1659.26 & & 39972.3 & & 800 \\
\hline
\end{tabular}




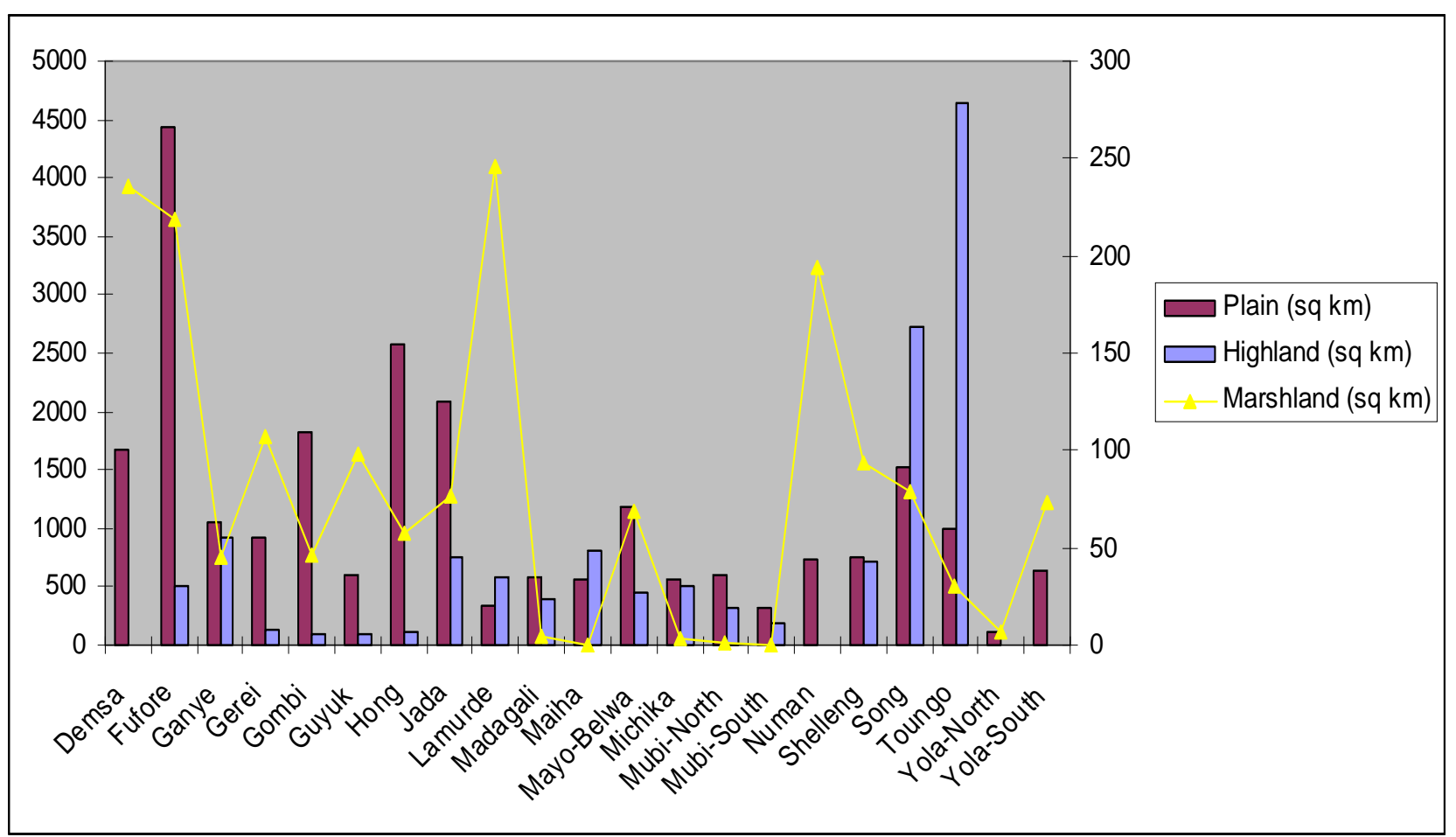

